\title{
LA DINÁMICA SOCIOAMBIENTAL EN EL ESPACIO SANTACRUCEÑO. PECULIARIDADES DE LA RELACIÓN ENTRE LA POBLACIÓN Y EL MEDIO NATURAL DESDE UNA PERSPECTIVA GEOGRÁFICA
}

\section{THE SOCIO-ENVIRONMENTAL DYNAMICS IN THE SANTA CRUZ AREA. PECULIARITIES OF THE RELATIONSHIP BETWEEN THE POPULATION AND THE NATURAL ENVIRONMENT FROM A GEOGRAPHIC PERSPECTIVE}

\author{
Dante Edin Cuadra \\ Profesor e Investigador del Dpto. de Geografía de la UNNE \\ dantecuadra@yahoo.com
}

\section{Sumario}

La provincia de Santa Cruz conforma un espacio de excepción desde el punto de vista natural, que ha potenciado efectos favorables y desfavorables según las valorizaciones externas a las que han estado sujetos sus recursos naturales a través del tiempo. Desde fines del siglo XIX a comienzos del $\mathrm{XXI}$ este territorio ha pasado por un proceso de transformaciones, en el que se reconocen ciclos geohistóricos impulsados por el aprovechamiento económico de sus recursos, que han tenido como común denominador un costo ambiental en el cual han desempeñado un papel relevante el componente político, el mercado externo, las características del poblamiento y del sistema natural implicado en las valorizaciones.

La metodología de trabajo se afirma en los postulados de la Geografía Histórica, combinando estrategias que permiten integrar las visiones cuantitativa, sistémica, ambiental, regional y sociocultural.

Lo original de esta investigación radica, primeramente, en reconocer y demostrar que se trata de un espacio natural singular; luego, en aportar un análisis evolutivo de la ocupación humana de este territorio, detallando exhaustivamente la composición de la población y su dinamismo y, por último, en identificar áreas diferenciadas y ciclos geohistóricos en los que se llevó a cabo el proceso socioeconómico, advirtiendo los efectos que los mismos han ido generando en el ambiente, entendido éste como la conjunción de elementos naturales y antrópicos.

Esta visión integradora del espacio y del tiempo, se presenta como insumo muy útil para entender la organización funcional de este ambiente $\mathrm{y}$, de ese modo, proponer una planificación territorial ajustada a la realidad.

\begin{abstract}
The province of Santa Cruz is a space of exception from the natural perspective, which has boosted favourable and unfavourable effects according to the external valuations to which natural resources have been subjected over time. Since the end of the 19th century to the beginning of the 21st this territory has gone through a process of transformation, in which are recognized geo-historical cycles driven by the economic exploitation of its resources. Those cycles have had as a common denominator an environmental cost in which have played a significant role the political component, the external market, and the characteristics of population and the natural system involved in the valuations.
\end{abstract}

The work methodology is based in the postulates of Historical Geography, combining strategies that integrate quantitative, systemic, environmental, regional and socio-cultural visions.

The originality of this research is, first of all, acknowledge and demonstrate that this is a unique natural area; then, provide an evolutionary analysis of human occupation of this territory, thoroughly detailing

Publicado en formato digital: Dr. Dante Edin Cuadra. LA DINÁMICA SOCIOAMBIENTAL EN EL ESPACIO SANTACRUCEÑO. PECULIARIDADES DE LA RELACIÓN ENTRE LA POBLACIÓN Y EL MEDIO NATURAL DESDE UNA PERSPECTIVA GEOGRÁFICA. RESÚMENES DE TESIS. Revista Geográfica Digital. IGUNNE. Facultad de Humanidades. UNNE. Año 11. № 22. Julio - Diciembre. 2014. ISSN 1668-5180 Resistencia, Chaco. 
the composition of the population and its dynamism and, finally, to identify differentiated areas and geo-historical cycles in which the socio-economic process was carried, warning the effects that they have been generating in the environment, understood this as a combination of natural and anthropic factors.

This inclusive view of space and time is presented as a very useful input to understand the functional organization of this environment and, thereby, suggest a territorial planning adjusted to reality.

\section{Palabras claves}

Santa Cruz; Society; Environment; Unique natural space; Economic activities; Geo-historical cycles.

\section{Keywords}

Santa Cruz; Sociedad; Ambiente; Excepcionalidad natural; Actividades económicas; Ciclos geohistóricos.

\section{Introducción}

La dirección de la tesis estuvo a cargo del Dr. Enrique D. Bruniard y fue defendida en 2011 con una calificación de sobresaliente (diez). El tesista vivió 15 años en la provincia de Santa Cruz, desarrollando parte de su trayectoria como investigador en la Universidad Nacional de la Patagonia Austral y, a través de convenios, en la E.E.A. Río Gallegos del INTA. Esa experiencia laboral, los conocimientos adquiridos -tanto a nivel teórico como en trabajos de campo- y los contactos personales e institucionales que se plasmaron al integrar distintos equipos interdisciplinarios durante muchos años, fueron desencadenantes al momento de elegir la problemática que guiaría el desarrollo de la tesis. Como se puede imaginar, es muy difícil reducir una tesis doctoral de casi 300 hojas (tamaño oficio), con numerosas tablas de datos, mapas, gráficos, esquematizaciones y fotografías, a unas cuantas páginas con el propósito de conformar un artículo o resumen. Pero, al menos, se ha intentado presentar un esbozo para que el lector tenga algunas ideas del contenido del trabajo y, de resultarle interesante, pasar a leer la tesis completa.

En el trabajo realizado, se parte de la concepción que Santa Cruz (como parte de la Patagonia) constituye un espacio de excepción desde el punto de vista natural, caracterizado por la fragilidad de sus ecosistemas, al tratarse de un ámbito templado frío marítimo, pero árido. Un espacio de excepción o singular significa que es único en su género, un verdadero laboratorio de pruebas, al no contarse con una situación paralela o similar en otros puntos del globo. El segundo elemento es la decisión e impulso de políticas externas a la región que han determinado la explotación de distintos recursos naturales a través del tiempo, que han alentado el poblamiento-despoblamiento del territorio. Al mismo tiempo, la propia actividad económica ha sido una fuente de atracción y de demanda de población, generando efectos, uno de ellos más perceptible e inmediato, como ha sido el dinamismo demográfico y socioeconómico y, otro más subrepticio hasta cierto punto, como es el daño producido en el ambiente. La combinación entre un "espacio singular", "políticas generadas fuera del territorio" y "población inmigrante o exógena" han conformado un tríptico para que la "actividad económica" y el "ambiente" se entrelazaran sin preverse las consecuencias, las que sólo el tiempo iría poniendo en evidencia y, en algunos casos, con crudeza, como ha sido la desertificación, el despoblamiento de las áreas rurales, los impactos de la minería y, consiguientemente, el deterioro de diversos ambientes naturales. Estos fenómenos enunciados merecen ser tratados integralmente, pero no sólo en tiempo presente, dado que obedecen a procesos que se han desencadenado en el transcurso de los años y, por lo tanto, reclaman un tratamiento desde la historicidad, razón por la que el trabajo se realizó desde la perspectiva de la geografía histórica. En otras palabras, se han reconocido los procesos geohistóricos desarrollados desde fines del siglo XIX hasta principios del XXI en el espacio santacruceño, sobre todo del poblamiento y, recíprocamente, de las actividades económicas,

Publicado en formato digital: Dr. Dante Edin Cuadra. LA DINÁMICA SOCIOAMBIENTAL EN EL ESPACIO SANTACRUCEÑO. PECULIARIDADES DE LA RELACIÓN ENTRE LA POBLACIÓN Y EL MEDIO NATURAL DESDE UNA PERSPECTIVA GEOGRÁFICA. RESÚMENES DE TESIS. Revista Geográfica Digital. IGUNNE. Facultad de Humanidades. UNNE. Año 11. No 22. Julio - Diciembre. 2014. ISSN 1668-5180 Resistencia, Chaco. 
Revista Geográfica Digital. IGUNNE. Facultad de Humanidades. UNNE. Año 11. № 22.

Julio - Diciembre 2014. ISSN 1668-5180 Resistencia, Chaco

reconociéndose etapas o ciclos en los que dichos procesos se produjeron y sus implicancias ambientales a través del tiempo.

\section{Objetivo General:}

Interpretar las implicancias sociales y ambientales del proceso geohistórico del poblamiento y del desarrollo económico, desde 1895 en adelante en el territorio de Santa Cruz.

\section{Objetivos Específicos:}

-Describir los caracteres de excepcionalidad natural del espacio santacruceño.

-Analizar los procesos demográficos desarrollados desde fines del siglo XIX hasta comienzos del XXI en el territorio santacruceño.

-Caracterizar los procesos de desarrollo económico en la provincia de Santa Cruz.

-Identificar ciclos o etapas con caracteres geográfico-históricos diferenciados desde los puntos de vista socio-demográfico, económico y ambiental a lo largo del período considerado.

-Determinar los efectos sociales y ambientales de las intervenciones humanas en función de los procesos de valorización de los recursos naturales en cada ciclo geohistórico identificado a lo largo del período considerado.

\section{Desarrollo}

\section{Configuración natural}

Se ha remarcado que Santa Cruz constituye un espacio de excepción o de singularidad natural. Este rasgo responde a una asociación de factores, que se explicará a continuación y que constituye un aspecto esencial para comprender muchos de los procesos que se han desarrollado en este espacio geográfico:

a) Excepcionalidad a escala planetaria: el territorio de Santa Cruz constituye una porción continental única en el mundo por su ubicación geográfica, ya que no existe otro continente entre los $46^{\circ}$ y $52^{\circ}$ de latitud Sur, sino algunas tierras insulares como es el caso del extremo Sur de Nueva Zelandia e islas pequeñas, especialmente en el Océano Pacífico. Los continentes ubicados en esas latitudes en el hemisferio Norte no resultan comparables por tratarse de condiciones totalmente diferentes: grandes superficies continentales $y$, por tanto, acentuada continentalidad, a lo que se le suma la función relevante que cumple la corriente cálida del Golfo que entibia el Norte europeo. En el extremo Sur de América el fenómeno es inverso: es un clima marítimo, carente del efecto continentalidad; las corrientes oceánicas de Humboldt en el Pacífico y de Malvinas en el Atlántico son frías y, en consecuencia, transfieren sus bajas temperaturas a las áreas emergidas. La proporción de tierras emergidas es escasa en el hemisferio Sur y, sobre todo, más allá de los $46^{\circ}$ de latitud: del total mundial sólo el $3 \%$ de las tierras se encuentran a la latitud de $46^{\circ}, 2 \%$ a los $50^{\circ}, 1 \%$ a los $55^{\circ}$ y $0 \%$ a $\operatorname{los} 60^{\circ}$.

b) Excepcionalidad a nivel nacional: Santa Cruz ocupa el extremo meridional de la Argentina continental, siendo el área más periférica del país junto a la isla de Tierra del Fuego, separada del área metropolitana por más de $2.000 \mathrm{~km}$. Durante mucho tiempo, Santa Cruz ha estado más conectada con el Sur de Chile que con el resto de la Argentina, conformando un área de gran autonomía que respondía a Punta Arenas como cabecera regional, sobre todo a fines del siglo XIX y comienzos del XX. Tal dinámica resultaba, en gran parte, de la conjugación de algunos hechos naturales, tales como la presencia del estrecho de Magallanes (unión de los océanos Atlántico y Pacífico), la baja energía del relieve del Sur santacruceño, las distancias relativamente cortas entre

Publicado en formato digital: Dr. Dante Edin Cuadra. LA DINÁMICA SOCIOAMBIENTAL EN EL ESPACIO SANTACRUCEÑO. PECULIARIDADES DE LA RELACIÓN ENTRE LA POBLACIÓN Y EL MEDIO NATURAL DESDE UNA PERSPECTIVA GEOGRÁFICA. RESÚMENES DE TESIS. Revista Geográfica Digital. IGUNNE. Facultad de Humanidades. UNNE. Año 11. № 22. Julio - Diciembre. 2014. ISSN 1668-5180 Resistencia, Chaco. 
esta porción de Santa Cruz y la costa chilena y, además, una notable homogeneidad de los caracteres fisiográficos a uno y otro lado del límite internacional.

Tradicionalmente ha sido un espacio caracterizado por el aislamiento, el que ha obedecido fundamentalmente a cuatro factores: grandes distancias del poder central, amplitud territorial (es la segunda provincia en superficie: $243.943 \mathrm{~km}^{2}$ ), topografía irregular con dificultades de accesibilidad y, por último, un clima exigente para la instalación humana (frío y nevadas otoño-invernales y ventoso en primavera-verano) con caracteres áridos y semiáridos en gran parte de su extensión. Casi la mitad del territorio, alrededor de $1.200 \mathrm{~km}$., limita con Chile (Oeste y Sur), en su frente oriental se halla el océano Atlántico (950 km. de costa), siendo su vínculo continental con el país su extremo septentrional, coincidente con el límite interprovincial con Chubut, de poco más de $300 \mathrm{~km}$.

Asimismo, Santa Cruz es la provincia que, dentro del territorio continental argentino, contiene el menor número de departamentos (sólo siete), por lo tanto, es la que en promedio tiene los departamentos más grandes. Inversamente, es una de las provincias argentinas con menor densidad demográfica: 0,8 hab/km² en 2001 y 1,1 hab/km² en 2010 (luego de Tierra del Fuego, Antártida e islas del Atlántico Sur). (INDEC, 2001 y 2010).

c) Excepcionalidad climática: en Santa Cruz se da el fenómeno del predominio absoluto del clima frío (promedio anual inferior a $10^{\circ} \mathrm{C}$ ) en una latitud media (entre 46 y $52^{\circ}$ Sur), donde serían esperables temperaturas medias superiores.

Allí mismo se da un hecho poco común, como es la coexistencia de la oceanidad con la aridez en todo el ámbito extra-andino. El régimen marítimo es el más extendido, con mayores montos pluviométricos en otoño-invierno y una amplitud térmica anual moderada que, de Sudoeste a Noreste, oscila entre 10 y $14^{\circ} \mathrm{C}$.

Se da la predominancia de los vientos Occidentales, que se originan en el anticiclón del Pacífico Sur y que, debido a la fuerza de Coriolis, inflexionan hacia el Sur, enfriándose en latitudes y aguas subantárticas antes de su ingreso al continente. Lo que se observa es una proyección hacia el Este de los efectos del Pacífico, que queda evidenciada en el régimen pluviométrico mediterráneo (precipitaciones de otoño-invierno) en gran parte de la provincia y un régimen subpolar (también Ilamado templado) en el Sur, que se manifiestan en la vegetación, dado que en el primero domina la estepa arbustiva abierta y, en el Sur, la estepa herbácea (pradera). Este último ambiente se caracteriza por una mayor regularidad anual de las precipitaciones.

"Los desarrollos meteorológicos están dominados... por los componentes ciclónicos de advección. Las depresiones que desde el Pacífico arriban a la costa chilena, presentan un sector caliente y húmedo que se eleva mediante vórtices entre dos y tres kilómetros de altura; el desplazamiento horizontal del aire en la zona frontal produce la elevación del aire cálido y a ello se agrega el efecto orográfico de obstáculo, de manera que la franja lluviosa puede alcanzar niveles mucho más elevados, e incluso, en aquellas montañas bajas, los máximos pluviométricos pueden registrarse a sotavento de las cumbres". (Bruniard, E., 1994)

La condición marítima influye decisivamente suavizando las temperaturas y, consiguientemente, moderando las amplitudes térmicas, pero no tiene una incidencia relevante sobre las precipitaciones en el ámbito extra-andino. En el Oeste, el factor orográfico es desencadenante del descenso térmico y de la condensación de la humedad aportada por los vientos Occidentales que provienen del flanco polar del anticiclón subtropical del Pacífico.

d) Límites geomorfológicos definidos que condicionan a otros factores geográficos: por un lado, una franja occidental cordillerana con ciertas discontinuidades e irregularidades topográficas, con mayor pluviosidad y presencia de lagos, glaciares, cabeceras fluviales, bosques, pastizales húmedos y tundra. Es el área de sombra pluviométrica, que se beneficia con el ascenso de los vientos del Oeste, que depositan su humedad sobre laderas y valles donde se dan las condiciones óptimas de presión parcial del vapor de agua para generar precipitaciones, conformando un espacio con exceso en el balance hídrico.

Publicado en formato digital: Dr. Dante Edin Cuadra. LA DINÁMICA SOCIOAMBIENTAL EN EL ESPACIO SANTACRUCEÑO. PECULIARIDADES DE LA RELACIÓN ENTRE LA POBLACIÓN Y EL MEDIO NATURAL DESDE UNA PERSPECTIVA GEOGRÁFICA. RESÚMENES DE TESIS. Revista Geográfica Digital. IGUNNE. Facultad de Humanidades. UNNE. Año 11. № 22. Julio - Diciembre. 2014. ISSN 1668-5180 Resistencia, Chaco. 
Por otro lado, un ámbito de mesetas escalonadas que bajan hacia el oriente, con valles que las atraviesan de Oeste a Este por donde discurren ríos alóctonos, en ambientes áridos y semiáridos, con desarrollo de estepas subdesérticas. Esta aridez de sotavento se produce por la interposición de la cordillera andina que intercepta la humedad de los vientos dominantes del Pacífico que, al descender al área de mesetas, eleva su temperatura y reduce su humedad relativa, alejándose de los umbrales de condensación. El resultado es un clima frío, marítimo y ventoso sobre la Patagonia extraandina, con déficit hídrico y regímenes fluviales de precipitación y deshielo.

e) La heterogeneidad del cordón andino: la cordillera de los Andes no es uniforme, ni continua y, por tanto, las precipitaciones, como otros componentes fisiográficos son diferenciados dentro de este ámbito. El relieve montañoso presenta las mayores alturas en el tramo central (donde se combinan los glaciares, lagos y bosques), aunque con interrupciones; hacia el Norte la altimetría es algo menor $y$, hacia el Sur, donde el modelado glaciar ha sido muy intenso, la cordillera es baja y cortada por valles. Debido a estas características, los bosques de Santa Cruz son estrechos y discontinuos. "Inmerso en el dominio de los vientos planetarios del Oeste, el elevado murallón andino actúa como el gran condensador de la humedad atmosférica que concentra en el ambiente montañoso las reservas hídricas suficientes para alimentar la red desagüe que se desarrolla en la vertiente oriental; y esa misma concentración del agua disponible contribuye a la condición desértica del gran espacio de sotavento, allí donde esa red hidrográfica adquiere su carácter alóctono". (Bruniard, E., 1994)

La variabilidad de energía de la faja montañosa genera contrastes muy marcados a nivel térmico y pluviométrico. Donde se produce la ruptura de la continuidad orográfica, la meseta árida penetra hacia el Oeste hasta el límite con Chile, como ocurre en el área del lago San Martín y al Sur del lago Buenos Aires. Estos “...tramos más húmedos y más secos, ...parecen estar relacionados con la mayor o menor proximidad a la zona lluviosa de barlovento". "También los tramos secos de la vertiente oriental, ...como es aquél que va de 44 a $49^{\circ} \mathrm{S}$, parecen relacionarse con la mayor distancia que expresa el perfil entre la isohipsa de 1.000 metros y la línea de altas cumbres". (Bruniard, E., 1994)

f) Forma peninsular entre océanos en los que influyen corrientes marinas frías: el continente americano, en su extremidad austral, evidencia un notable estrechamiento, que le confiere una topología de península entre los océanos Pacífico y Atlántico Sur. Estas aguas se hallan en contacto con el Mar Glaciar Antártico, con la singularidad que las corrientes marinas frías de Humboldt del lado chileno occidental y de Malvinas en el lado oriental, se desplazan de Sur a Norte, produciendo un enfriamiento regional. La mayor condensación se produce en el Oeste, en función de la influencia altitudinal que ejerce la cordillera andina. La combinación de estos tres factores (forma peninsular, contactos interocéanicos y corrientes marinas frías) inciden en el régimen marítimo de este espacio y, en combinación con el relieve y los vientos, son los responsables de la pluviosidad en la franja andina y de la aridez en el ámbito extra-andino.

g) Prolongación oriental de los bosques australes sobre un área no andina: se trata de una singularidad observada en el Sudoeste de la provincia de Santa Cruz, donde se da el fenómeno que las especies arbóreas Nothofagus antarctica (ñire) y Nothofagus pumilio (lenga) y muchos de los componentes biológicos del complejo de cordillera se extienden a modo de una cuña en el sentido Oeste-Este a lo largo de $60 \mathrm{~km}$. hasta alcanzar el meridiano de $71^{\circ} 10^{`}$ Oeste, interrumpiendo un área dominada por la estepa graminosa. Lo excepcional de esta distribución no sólo radica en su alineación con los paralelos, característica que no vuelve a repetirse en la Patagonia, sino en que es el único lugar en el que esta formación fitogeográfica se desarrolla fuera del sistema andino, aprovechando el valle fluvial del Gallegos y el reparo que le brindan las bardas de la elevada Meseta Latorre al Norte del mismo. Esta singularidad ha sido muy beneficiosa para los estancieros radicados en el Sur de Santa Cruz a fines del siglo XIX, pues les permitía aprovisionarse de maderas (leña y otros usos) en la propia zona.

h) Incidencia del fenómeno "upwelling": consiste en la surgencia de aguas frías provenientes de las profundidades oceánicas, que se produce aproximadamente a los $60^{\circ}$ de latitud Sur. Este dinamismo oceánico de compensación térmica, química y biológica enfría las aguas que, luego, las corrientes

Publicado en formato digital: Dr. Dante Edin Cuadra. LA DINÁMICA SOCIOAMBIENTAL EN EL ESPACIO SANTACRUCEÑO. PECULIARIDADES DE LA RELACIÓN ENTRE LA POBLACIÓN Y EL MEDIO NATURAL DESDE UNA PERSPECTIVA GEOGRÁFICA. RESÚMENES DE TESIS. Revista Geográfica Digital. IGUNNE. Facultad de Humanidades. UNNE. Año 11. № 22. Julio - Diciembre. 2014. ISSN 1668-5180 Resistencia, Chaco. 
marinas empujan hacia el Norte, por lo que representa un elemento más dentro de los que generan un enfriamiento regional en estas latitudes medias.

Estas características tan particulares del extremo Sur de la Patagonia, gracias a la combinación especial de una gran diversidad de factores, nos permiten comprender ciertas contrariedades geográficas que, previo a este trabajo, constituían interrogantes altamente movilizadores. Esas aparentes contradicciones, como pueden ser: "un desierto con agua", "un clima oceánico árido", "glaciares al lado de los bosques", "una península árida en medio de los más grandes océanos", "excesos y carencias hídricas a cortas distancias", "estepa subdesértica en ambiente templado frío marítimo", "vientos intensos, baja humedad relativa y elevada evapotranspiración en un clima marítimo" o "cuña boscosa en un ámbito de mesetas y estepas" han sido desafiantes para entender el funcionamiento del sistema natural y, además, los efectos de la presencia y de las acciones humanas en un espacio realmente singular.

\section{Población y actividades económicas: los ciclos geohistóricos}

En cuanto a la evolución de los caracteres demográficos y económicos observados en este territorio, el siguiente gráfico evolutivo, encabezado por la sucesión de pirámides de población, resulta muy ilustrativo:

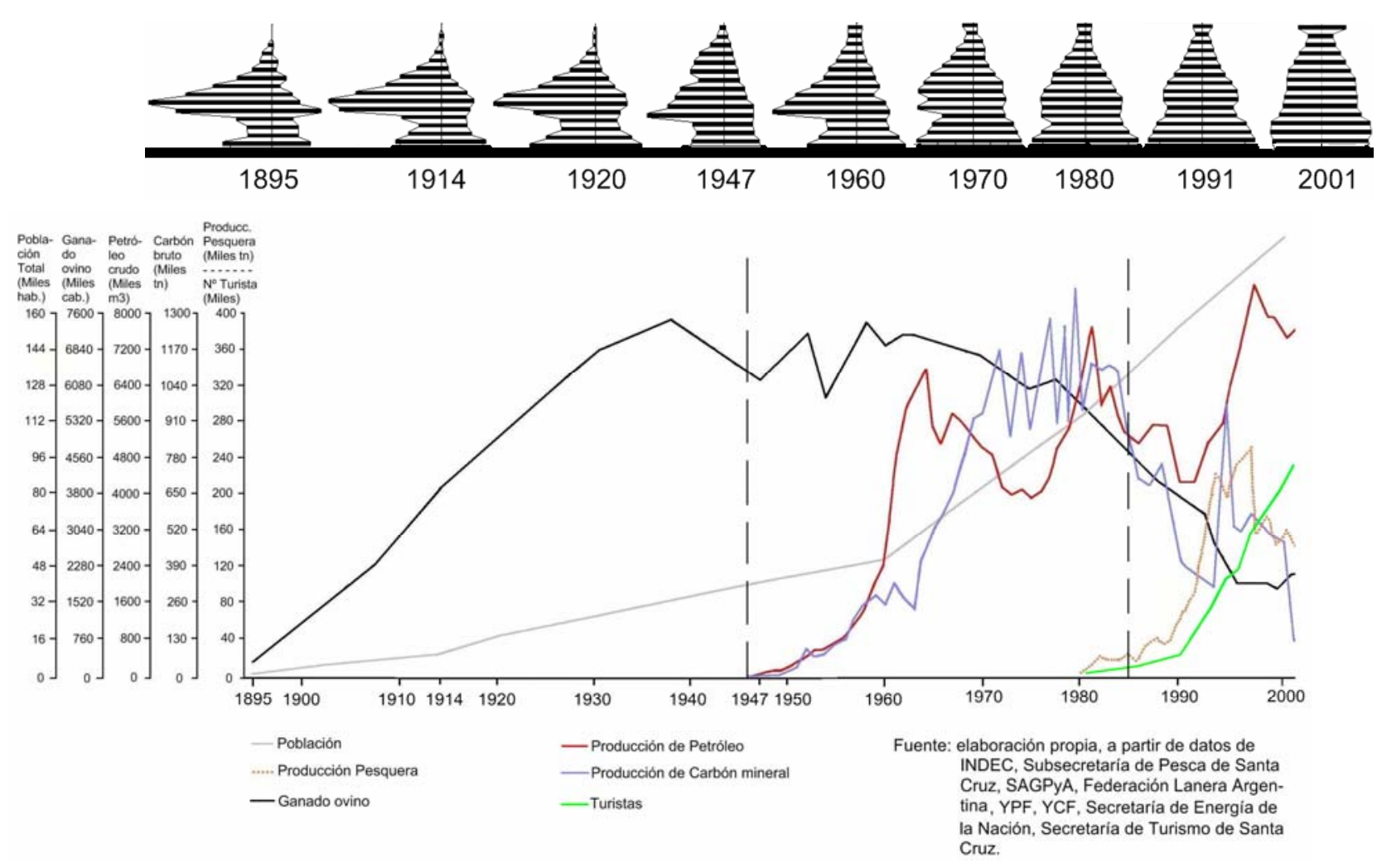

Al analizar el proceso demográfico-económico desarrollado en un ámbito de características naturales excepcionales, como es el de la provincia de Santa Cruz, se han podido definir nítidamente tres etapas, que son las siguientes:

a) Etapa del poblamiento inicial en función de la expansión ovina extensiva (fines del siglo pasado hasta la década del '40). b) Etapa del estancamiento y retroceso ovino e inicio y consolidación de la explotación estatal de recursos naturales no renovables (década del '40 hasta principios de los '80). 
c) Etapa de la diversificación económica (desde los años '80 hasta la actualidad), fuertemente basada en la explotación de los recursos tradicionales (sobre todo de petróleo y gas natural), ovinicultura en profunda crisis y potenciación de otras actividades económicas como la pesca, el turismo, la agricultura intensiva en pequeñas áreas, la explotación de minerales metalíferos de alto valor y rocas de aplicación con intervención, esencialmente, del sector privado -sobre todo a partir de la década de los '90-, en algunos casos con participación del Estado Provincial.

a) Etapa del poblamiento inicial en función de la expansión ovina extensiva: se desarrolló desde fines del siglo XIX hasta la década del ' 40 y está marcada por la ruptura de un equilibrio natural que hasta entonces se sostuvo, a pesar de la presencia humana. Este espacio, históricamente fue habitado por grupos autóctonos de cazadores seminómades de muy bajas densidades, recibió esporádicamente a la población blanca (navegantes, exploradores, cazadores de ballenas, corsarios y aventureros) en los siglos que sucedieron al "descubrimiento de América". Pero el poblamiento efectivo se dio a partir de las tres últimas décadas del siglo XIX de la mano de la ganadería ovina que, como actividad extensiva, sólo pudo generar algunos núcleos demográficos en la franja costera e instaló una población muy dispersa en todo el ámbito de las mesetas áridas y semiáridas que predominan en este territorio. Como actividad pionera, la ganadería fue relevante en los aspectos demográficos y económicos, incorporando un dinamismo antes inexistente en esta alejada porción del territorio argentino, más allá de que sus efectos acumulativos sobre el ambiente serían, más tarde, lamentables. Asimismo, le imprimió al paisaje una característica que se difundió en toda la región patagónica, con elementos típicos como los cascos de estancias, los galpones de esquila, los puestos, los alambrados, las pequeñas ciudades, los puertos de embarque y los frigoríficos sobre la costa. El crecimiento de la población fue lento, pero sostenido, con momentos de estancamiento, en tanto las estructuras demográficas se mostraban muy asimétricas, dado el carácter selectivo de la actividad rectora y las exigencias propias de un medio aislado, periférico, con caracteres y singularidades naturales ya descriptas. La organización político-administrativa de Santa Cruz, en su condición de Territorio Nacional, la ubicaba como un área muy centralizada, donde las decisiones del gobierno nacional se aplicaban directamente, como ha ocurrido con el desplazamiento y casi desaparición de las culturas originarias, el otorgamiento masivo de las tierras fiscales, la promoción de la ganadería ovina y de la inmigración de malvinenses y españoles, muchos de ellos ya radicados en el Sur de Chile.

Este territorio, que inicialmente gozaba de una gran autonomía junto al Sur chileno, fue integrándose rápidamente a la Argentina luego de: la creación del Territorio Nacional (1884), la pérdida de valor estratégico del puerto de Punta Arenas y del estrecho de Magallanes (al abrirse el canal de Panamá en 1914), la instalación de la aduana en 1912 y, de hecho, la llegada de inmigrantes europeos, pero también de argentinos que buscaban abrirse un futuro en estas latitudes.

Por entonces, el espacio contaba con escasa población, poca conectividad, fuerte direccionamiento del gobierno nacional, escasa integración social (en función del aislamiento, la dispersión demográfica y los distintos orígenes de su población), una monocultura ganadera y un incipiente desarrollo urbano sobre algunos puntos de la costa, donde -en varios casos- se sumaba la actividad portuaria y frigorífica.

b) Etapa del estancamiento y retroceso ovino e inicio y consolidación de la explotación estatal de recursos naturales no renovables: se desplegó entre los años ' 40 y comienzos de los '80. Si bien la actividad ganadera entró en una meseta, que luego se vería reflejada en la población (sobre todo rural), se dio inicio a otra actividad primaria promovida por el Estado Nacional, el cual no tardó en conformar empresas encargadas de impulsar el conjunto de acciones para que el extremo Sur se constituyera en la proveedora de petróleo, gas natural y carbón mineral para cubrir las demandas del área central del país. Esas empresas serían, más allá de algunos cambios iniciales de nominación, YPF (Yacimientos Petrolíferos Fiscales), YCF (Yacimientos Carboníferos Fiscales) y Gas del Estado.

El estacionamiento y posterior retroceso de la ganadería tuvo estrecha vinculación con que la instalación y desarrollo de esta actividad se produjo sobre ecosistemas áridos y subdesérticos, que fueron evidenciando los impactos generados por la sobrecarga animal en campos divididos geométricamente, cuyo criterio de delimitación no tuvo en cuenta la correcta distribución de los

Publicado en formato digital: Dr. Dante Edin Cuadra. LA DINÁMICA SOCIOAMBIENTAL EN EL ESPACIO SANTACRUCEÑO. PECULIARIDADES DE LA RELACIÓN ENTRE LA POBLACIÓN Y EL MEDIO NATURAL DESDE UNA PERSPECTIVA GEOGRÁFICA. RESÚMENES DE TESIS. Revista Geográfica Digital. IGUNNE. Facultad de Humanidades. UNNE. Año 11. № 22. Julio - Diciembre. 2014. ISSN 1668-5180 Resistencia, Chaco. 
recursos edáficos, hídricos, ni biológicos. El desconocimiento del potencial receptivo de estos ambientes, las faltas de control estatal, la avidez del mercado, las recurrentes crisis económicas y los deficientes mecanismos de acceso a la tierra, propiciaron la manifestación de procesos de desertificación que, con el paso de las décadas, se fueron agudizando. Las consecuencias, luego de los años '60, fueron: despoblamiento rural, cierre de establecimientos ganaderos, deficiencias productivas y endeudamiento, aumento de la población urbana y pérdida de un valioso capital cultural.

Las actividades petrolíferas, gasíferas y carboníferas fueron importantes paliativos, especialmente para el Noreste y Sur de Santa Cruz, pero el área más crítica desde el punto de vista ambiental y social ha sido el de las mesetas centrales áridas, donde la situación económica y demográfica se ha ido agravando con el paso de los años: pérdida de población, intensificación de los procesos de desertificación, clausuras sistemáticas de establecimientos ganaderos, aumento de desequilibrios estructurales en su constitución demográfica, deterioro de la infraestructura (tanto productiva, como vial) y, por ende, crecimiento de su marginalidad geográfica.

Los pueblos y ciudades beneficiados por las nuevas actividades han sido los situados en los departamentos Deseado (al Norte del río homónimo) y Güer Aike, que fueron -en consecuencia- los que adquirieron relevancia demográfica y económica en este período, aumentando así la asimetría geográfica en el territorio de Santa Cruz. Desde el punto de vista ambiental, la actividad minera vino a incrementar ciertos impactos, los más visibles sobre el suelo y la vegetación, aunque sus efectos se han extendido, en forma recurrente, a las aguas (tanto superficiales como subterráneas) y al aire. Las trazas sísmicas, las perforaciones, caminos, galpones, campamentos, áreas de almacenamiento, ductos y piletas fueron elementos que pasaron rápidamente a formar parte del paisaje en estos espacios.

La población incorporada por la producción de petróleo y gas natural ha sido de origen nacional, en tanto, la explotación carbonífera ha recibido un importante flujo de trabajadores del Sur de Chile. Los argentinos provenían de provincias con tradición minera, como La Rioja, San Juan, Catamarca, Salta y Jujuy.

Casi al promediar esta etapa, Santa Cruz pasó de ser un Territorio Nacional a constituirse en Estado Provincial, lo que le posibilitó el ejercicio político a nivel local, conformar un marco jurídico e institucional y adquirir mayor autonomía y participación dentro del ámbito nacional. No obstante, el costoso aprendizaje de los consensos cívicos y las repetidas interrupciones democráticas, no le permitieron un afianzamiento propio en esta etapa y siguió dependiendo, fuertemente, de las decisiones emanadas del gobierno central.

c) Etapa de la diversificación económica: se extiende desde los años ' 80 hasta la actualidad y se caracteriza por la presencia de actividades tradicionales en decadencia (como la ganadería extensiva ovina y la explotación de carbón mineral), la extracción de hidrocarburos con oscilaciones en su producción y otras, que se han ido incorporando y consolidando, como la pesca, la minería (la mayor expresión está dada por los yacimientos de oro y plata de Cerro Vanguardia), la agricultura intensiva y, sobre todo, la dimensión que fue adquiriendo el turismo en la provincia. Esta última actividad ha logrado su apogeo a partir de la década de los '90 y encuentra su máxima expresión en la franja cordillerana del departamento Lago Argentino.

A lo largo de estas etapas, las asimetrías estructurales de la población tendieron a reducirse en líneas generales, como puede apreciarse en la sucesión de pirámides que antecede.

\section{Las áreas geográficas socioambientalmente diferenciadas}

A nivel de las unidades espaciales que presentan caracteres socioambientales propios y, por tanto, identidad territorial dentro de la provincia de Santa Cruz, se han reconocido y caracterizado las siguientes:

En primer término, se destacan por su extensión las mesetas centrales áridas, casi deshabitadas y sin perspectivas económicas sustentables por el momento, con intensos procesos de desertificación

Publicado en formato digital: Dr. Dante Edin Cuadra. LA DINÁMICA SOCIOAMBIENTAL EN EL ESPACIO SANTACRUCEÑO. PECULIARIDADES DE LA RELACIÓN ENTRE LA POBLACIÓN Y EL MEDIO NATURAL DESDE UNA PERSPECTIVA GEOGRÁFICA. RESÚMENES DE TESIS. Revista Geográfica Digital. IGUNNE. Facultad de Humanidades. UNNE. Año 11. No 22. Julio - Diciembre. 2014. ISSN 1668-5180 Resistencia, Chaco. 
como consecuencia del impacto ganadero ovino sufrido durante décadas. Constituyen, salvo excepciones puntuales, un gran vacío demográfico en vías de seguir involucionando, donde ciertas áreas transitoriamente suman la actividad minera (la más importante: Cerro Vanguardia), que incrementa la criticidad del área desde el punto de vista ambiental y, por otro lado, no es generadora de nuevos asentamientos poblacionales. Algunos atractivos que ofrece este espacio para un incipiente turismo son: estancias turísticas, puntos costeros con paisajes y fauna singulares, los Bosques Petrificados y el Bajo de San Julián (105 m bajo el nivel del mar). Las localidades más representativas, en el Norte y centro de la provincia, son Perito Moreno y Gobernador Gregores. En este contexto de aridez se encuentran ríos que discurren de Oeste a Este (Chalía, Chico y Santa Cruz), lagos (Cardiel, Strobel, Quiroga, entre otros) y aguas subterráneas que constituyen recursos de gran potencial para la instalación de emprendimientos futuros.

La cultura autóctona fue prácticamente desmantelada con la privatización de las tierras entre finales del siglo XIX y las primeras décadas del XX. La traza de alambrados, la prohibición de ingreso a esas propiedades, la cacería de la fauna autóctona, sobre todo de los predadores y competidores de la oveja (zorros, liebres, guanacos, ñandúes) no dejó espacio para los hábitos de vida de los pueblos originarios, que fueron perseguidos inicialmente por los estancieros y, luego, mezclados con los criollos que llegaban a estas tierras; sin dudas, las reservas indígenas no fueron solución para la recuperación y consolidación de estos pueblos. Las pautas culturales de los argentinos e inmigrantes lograron imponerse con el paso del tiempo, extendiéndose la época de esplendor hasta la década del '30, aunque nunca el área pudo alcanzar un equilibrio demográfico, ni siquiera económico y, menos, ambiental. La escasa densidad demográfica, los altos índices de masculinidad, el proceso de envejecimiento de la población rural, la elevada deserción escolar y la emigración son demostrativos de la problemática vivida por este espacio.

En segundo lugar, el área petrolífero-gasífera de la cuenca de San Jorge, con una fuerte e intensa explotación del subsuelo y marcados impactos sobre la superficie terrestre: líneas sísmicas o picadas, caminos, pozos, piletas, ductos, bombas, tanques, etc., con frecuentes derrames y contaminación de los suelos, la vegetación, las aguas superficiales y subterráneas y el aire. Se caracteriza por tener población concentrada en núcleos urbanos y campamentos que, con el transcurso del tiempo, se van desmantelando. La fortaleza demográfica y económica del área es totalmente dependiente de la existencia del recurso, de allí que se los considere asentamientos de enclave. Una vez agotado el mismo, sobreviene un período de crisis y despoblamiento, excepto que alguna actividad alternativa recepcione la mano de obra liberada.

El puerto de Caleta Olivia, junto con el transporte terrestre, ofician de salida de la producción petrolífera de estas extensas áreas de mesetas interiores en donde sobresalen Pico Truncado, Las Heras y Cañadón Seco. Es un espacio que ya vino sufriendo impactos por sobrepastoreo durante la primera mitad del siglo $X X$-con el consecuente despoblamiento rural- y que integra la parte septentrional de las mesetas áridas centrales, ubicada al Norte del río Deseado.

La estructura demográfica se ha caracterizado por el desequilibrio, debido a la demanda selectiva (varones jóvenes) de las actividades económicas dominantes (ganadería y explotación de hidrocarburos); el área sufrió un proceso de envejecimiento y, a partir de 1980, se observa una tendencia hacia el equilibrio en virtud del debilitamiento de los ingresos de población y del fortalecimiento experimentado por el crecimiento vegetativo. Este espacio ha sido escenario de distintas culturas a través del tiempo: la originaria (prácticamente desaparecida, sólo presente en la toponimia y en los restos arqueológicos), la ovinícola (de la que aún quedan relictos) y la minera (todavía gravitante), que se amalgaman en el presente, otorgándole caracteres distintivos al área.

El extremo austral de Santa Cruz, donde se localiza la pradera o estepa graminosa, tradicionalmente ganadera, de clima frío y algo más húmeda, no evidencia impactos tan intensos por sobrepastoreo debido a condiciones ecológicas más favorables (cobertura de gramíneas y mallines sobre mesetas bajas y valles fluviales, con suelos potencialmente más eficientes para la actividad agropecuaria y menos impactables ante condiciones de alta presión ganadera). Contiene a la capital provincial y dispone de población rural en sus áreas interiores. Se comunica hacia el Norte por medio de la ruta 3, con Río Turbio y Calafate por rutas 283 y 40 y, además, con la República de Chile. Posee petróleo y

Publicado en formato digital: Dr. Dante Edin Cuadra. LA DINÁMICA SOCIOAMBIENTAL EN EL ESPACIO SANTACRUCEÑO. PECULIARIDADES DE LA RELACIÓN ENTRE LA POBLACIÓN Y EL MEDIO NATURAL DESDE UNA PERSPECTIVA GEOGRÁFICA. RESÚMENES DE TESIS. Revista Geográfica Digital. IGUNNE. Facultad de Humanidades. UNNE. Año 11. № 22. Julio - Diciembre. 2014. ISSN 1668-5180 Resistencia, Chaco. 
gas en la franja oriental y un puerto de aguas abiertas sobre el mar Argentino Los impactos ambientales son más atenuados que en la zona Norte, al tratarse de yacimientos menos dimensionados y espacialmente más constreñidos. Es el espacio colonizado más tempranamente por inmigrantes británicos, españoles y yugoslavos y, asimismo, el que recibió más población chilena, especialmente luego de los años '40. A través del tiempo ha evidenciado una evolución demográfica más sólida que las restantes jurisdicciones: mayor densidad y asistencia escolar rural, menores índices de masculinidad y de envejecimiento y continuidad de las explotaciones agropecuarias a través del tiempo. La población aborigen cuenta con una reserva en Camusu Aike y se conservan de su cultura una rica toponimia, algunas pinturas rupestres, expresiones musicales, su léxico y tradiciones, que han sido compendiados en textos, diccionarios y soportes informáticos, ya que sus hábitos de vida han sido modificados a partir de la colonización.

Indudablemente, el emplazamiento de la ciudad capital en el oriente de este espacio le ha otorgado un rol muy especial al área, tanto desde el punto de vista demográfico, como socioeconómico: mayor densidad y equilibrio en su composición, diversificación de las ramas de actividad (sobre todo en el sector terciario), mayor masa crítica en términos políticos, sociales, educativos y culturales, relevancia institucional y política y, por ende, más receptiva a las innovaciones culturales y tecnológicas.

La cuenca del río Turbio ha sido tradicionalmente un enclave minero ubicado en el Sudoeste de la provincia, la única explotación importante de carbón mineral del país, en un ambiente de montañas rebajadas por las glaciaciones del cuaternario, bosques y estepas graminosas influidos por la humedad proveniente del Pacífico. Las sucesivas crisis de producción -especialmente luego de los años '80- ha sumergido a este espacio en un escenario lleno de dificultades en los planos económico, demográfico y social, sin ignorar los efectos contaminantes de la actividad minera sobre suelos, aguas y aire. Su comunicación con Chile ha sido siempre muy estrecha y su producción ha salido históricamente por el puerto de Río Gallegos, previo transporte por ferrocarril. Actualmente se ha incorporado la actividad turística geológica e invernal, a la vez que es paso obligado para pasar a Puerto Natales (situada sobre la costa de fiordos del océano Pacífico) en Chile, desde donde ha provenido gran parte de la mano de obra demandada por la actividad minera.

Este espacio ha conformado tradicionalmente un sector periférico, tanto de Santa Cruz como del país, con dificultades en las comunicaciones, sobretodo durante la exigente estación invernal, caracterizado por fuertes desequilibrios demográficos en función de la demanda laboral minera (varones jóvenes solteros): elevada masculinidad, edad media moderada, escasa población nacida en el lugar, alta tasa de extranjeros -mayormente chilenos- y baja escolaridad de la masa trabajadora. A ello se le suma el crecimiento inicial desordenado de los núcleos y una fuerte emigración luego de 1980. El mayor peso demográfico dentro de la cuenca lo tienen Río Turbio y 28 de Noviembre. La cultura autóctona ha dejado muy pocos vestigios en la zona.

El área turística cordillerana glacial, lacustre y boscosa tiene su cabecera en la villa de Calafate (próxima al lago Argentino), a la que se sumó en los últimos años El Chaltén (fundada en 1985, al Norte del lago Viedma), de gran atractivo nacional e internacional, que motoriza fuertemente al área, especialmente luego de la década de 1980. Hoteles, estancias turísticas, paseos en yates en los lagos Argentino y Viedma, tracking, pesca, caminatas sobre el hielo, alpinismo, flora y fauna autóctonas en el Parque Nacional Los Glaciares (declarado Patrimonio de la Humanidad por la UNESCO en 1982) y el rompimiento del glaciar Perito Moreno son algunas de las opciones que ofrece el área a los miles de visitantes cada año. El carácter prístino del paisaje, debido a la escasa interferencia del hombre en gran parte de este ambiente, la inexistencia de industrias u otras actividades impactantes le otorgan un plus de alto valor escénico natural, muy valorado por el turismo internacional.

La composición demográfica ha presentado siempre signos de desequilibrio, en principio por ser un área periférica, poco comunicada y esencialmente ganadera (hasta 1980) y, posteriormente, por experimentar un crecimiento urbano explosivo a expensas de la inmigración nacional enlazada con el fuerte desarrollo turístico del área y actividades conexas (hoteles, cabañas, restaurantes, empresas de transportes, casas de artesanías y variedad de servicios y negocios). Este dinamismo también fue

Publicado en formato digital: Dr. Dante Edin Cuadra. LA DINÁMICA SOCIOAMBIENTAL EN EL ESPACIO SANTACRUCEÑO. PECULIARIDADES DE LA RELACIÓN ENTRE LA POBLACIÓN Y EL MEDIO NATURAL DESDE UNA PERSPECTIVA GEOGRÁFICA. RESÚMENES DE TESIS. Revista Geográfica Digital. IGUNNE. Facultad de Humanidades. UNNE. Año 11. № 22. Julio - Diciembre. 2014. ISSN 1668-5180 Resistencia, Chaco. 
efecto del mejoramiento de la infraestructura vial y aeroportuaria. Se halla conectada con la cuenca del Turbio y con Río Gallegos por rutas pavimentadas. La cultura de los pueblos originarios ha desaparecido de esta zona casi por completo.

La comarca del Noroeste está ubicada en un espacio donde los factores geográficos generan un clima local más propicio para la instalación humana y, particularmente, de la actividad agrícola. Se emplaza al Sur del lago Buenos Aires, configurando un ambiente benigno, donde se comunican las localidades de Los Antiguos (Santa Cruz, Argentina) con Chile Chico en el país vecino. El abrigo que constituye el contacto de las mesetas altas con el área cordillerana en un valle transversal labrado por las últimas glaciaciones, las terrazas glaciales resultantes y la magnitud del lago Buenos Aires, le dan al área una belleza paisajística singular. La implantación de chacras de cultivos, sobre todo de frutas finas le agrega una fisonomía muy atractiva a este espacio, donde anualmente se realiza la Fiesta Provincial de la Cereza, que convoca a una gran cantidad de público y artistas. La presencia de pinturas rupestres a corta distancia fomenta el turismo cultural, dado que en este lugar vivían su ancianidad los tehuelches del Norte cuando ya no podían llevar una vida seminómade basada en la caza del guanaco. El contacto más fluido de esta población es con Perito Moreno, Las Heras, Pico Truncado, Caleta Olivia y Comodoro Rivadavia, a través de rutas pavimentadas. La estructura demográfica ha sido bastante desequilibrada durante la etapa ganadera (masculinidad, edad media y analfabetismo acentuados), pero a partir de los años '80, con la introducción de la agricultura, las asimetrías se han ido corrigiendo.

Puntos costeros intermedios como Puerto Deseado, Puerto San Julián, Puerto Santa Cruz, la reserva nacional Monte León y Comandante Luis Piedra Buena (esta última localidad ubicada a orillas del río Santa Cruz, muy cercana a la isla Pavón) se caracterizan en su mayoría por conformar poblaciones pequeñas, puertos pesqueros y ofrecer alternativas turísticas aún no muy desarrolladas (reservas costeras y marinas, crustáceos fósiles, pesca, camping, circuitos locales que unen la estepa con el mar, observación de fauna marina o vestigios de actividades pioneras: estancias, frigoríficos, muelles, museos). Estos ambientes de mesetas bajas y estepas, estuarios, costas acantiladas y playas pedregosas albergan una interesante fauna autóctona (cormoranes, gaviotas, chorlos, pingüinos, bandurrias, liebres, zorros, pichis, ñandúes, guanacos, lobos marinos, etc.). En su entorno predomina la aridez, en extensas áreas frío-ventosas tradicionalmente ganaderas que dejan en evidencia los efectos de décadas de sobrepastoreo: suelos expuestos, erosión eólica, médanos activos, estancias abandonadas, vacíos demográficos. La influencia marítima en esta franja se produce, sobre todo, sobre las temperaturas (amplitudes moderadas), ya que las precipitaciones anuales apenas superan los $250 \mathrm{~mm}$, debido a la predominancia de los vientos secos del Oeste y Sudoeste, la escasa altura del relieve y la frialdad de las aguas atlánticas donde discurre la corriente fría de Malvinas que transporta aguas subantárticas de Sur a Norte. La composición demográfica ha estado muy condicionada por la ganadería del entorno, especialmente hasta mediados del siglo XX (masculinidad elevada, marcado envejecimiento, ocupaciones selectivas), pero sus caracteres urbanos $-\mathrm{y}$ en algunos casos portuarios e industriales- han ido reduciendo esas asimetrías. El fortalecimiento del crecimiento vegetativo y la proliferación de las actividades terciarias, luego de 1980, ayudaron en ese sentido. 


\section{PROVINCIA DE SANTA CRUZ: ÁREAS SOCIOAMBIENTALES}

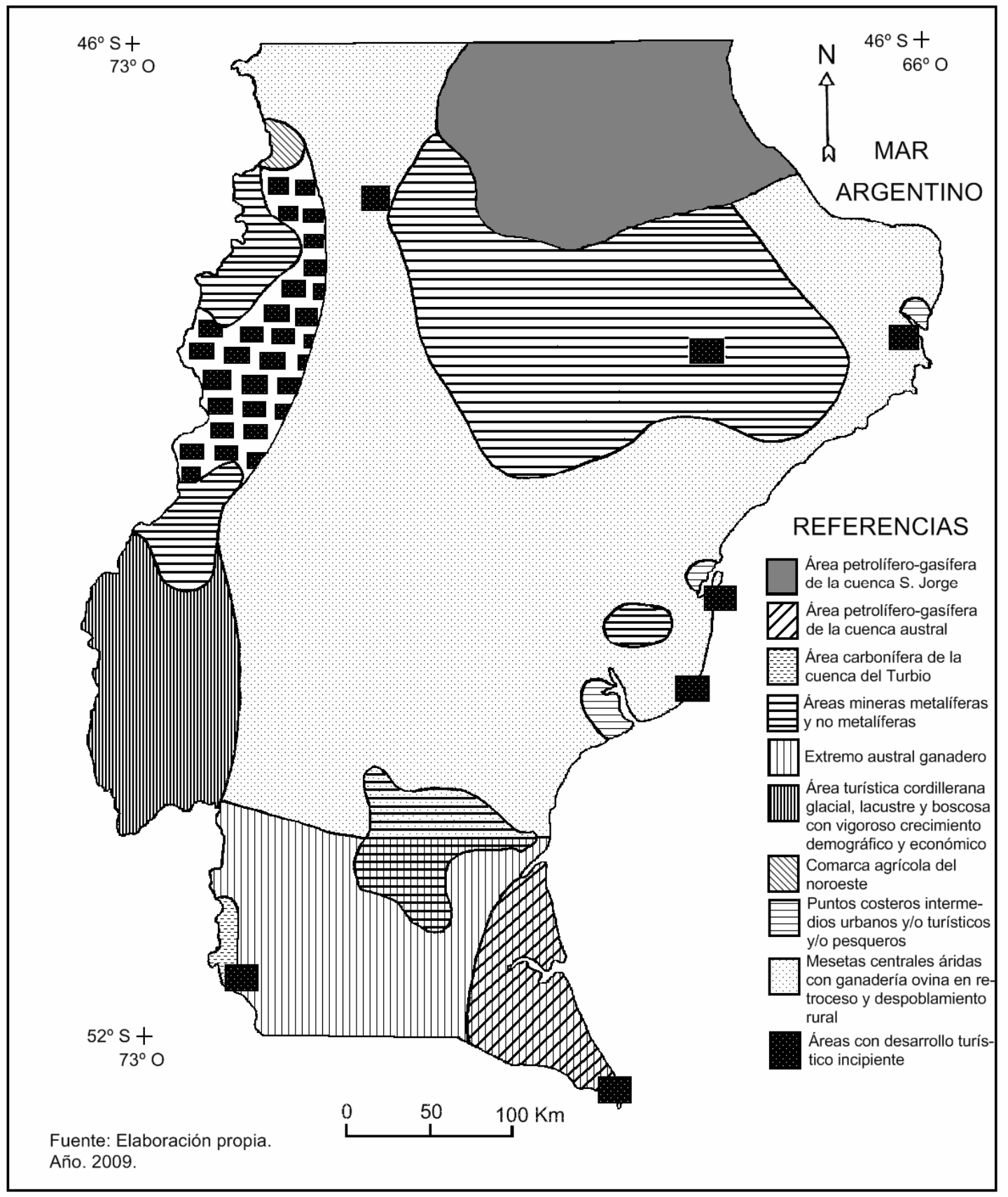

\section{Consideraciones finales}

El espacio santacruceño ha sido escenario de una relación, en cierto modo, traumática entre el hombre y la naturaleza en gran parte de su extensión. La armonía o equilibrio estuvo presente mientras los grupos amerindios habitaron el área (entre el 10.000 a.p. y fines del siglo XIX), dado que estos pueblos cazadores seminómades utilizaban los recursos de la naturaleza sólo para satisfacer sus necesidades de alimentación, abrigo, vivienda y para construir los artefactos que les permitían desarrollar sus actividades de supervivencia; las densidades de estos grupos humanos fueron muy bajas y el uso que hicieron de los recursos fue limitado y de poca intensidad. 
Desde el siglo XVI, durante el dominio español, la llegada de embarcaciones, los recorridos exploratorios e, incluso, la instalación de algunos asentamientos transitorios, no dejaron huellas sobre el medio natural. Posteriormente, durante la etapa independiente (después de 1816), no se conocen antagonismos entre el hombre y la naturaleza, pues este territorio periférico de la Argentina se mantuvo postergado y casi olvidado hasta el último cuarto del siglo XIX.

Recién con la generación del ' 80 y las ideas liberales que tomaron fuerza en el país, la Patagonia fue parte del interés político y estratégico estatal, impulsándose la Campaña del Desierto, el delineamiento de los Territorios Nacionales, la promoción de la inmigración y la entrega efectiva de tierras a los recién llegados. En ese contexto se inició lo que, con el transcurso de las décadas, sería el primer impacto general que desestabilizaría a los ecosistemas o equilibrios naturales: la colonización de estas tierras de la mano de la ganadería ovina extensiva, la cual traería efectos devastadores sobre la vegetación, el suelo y el propio sistema productivo, demográfico y social del extendido espacio extra-andino, especialmente de las mesetas áridas y semiáridas centrales.

La vulnerabilidad ambiental y social de este espacio es considerablemente alta, la calidad de vida ha ido decayendo en las últimas seis décadas, en tanto, la situación demográfica se muestra frágil y poco sustentable. El manejo no sostenible de la actividad ganadera, el desconocimiento del potencial productivo de los campos, la carencia de marcos legales adecuados, la tardanza de legislaciones apropiadas y la falta de controles fueron los componentes esenciales para que este espacio, el más castigado de la provincia, presente actualmente los peores indicadores sociales, económicos y ambientales.

El proceso de conquista, poblamiento e implementación de actividades económicas se desarrolló sin tener en cuenta los caracteres singulares o excepcionales de este espacio geográfico. La especial combinación de factores naturales en el extremo Sur de América, no le permitieron al poblador europeo, ni al argentino, interpretar adecuadamente los efectos de su intervención.

Este ambiente, casi peninsular, inserto entre dos océanos fríos en latitudes medias, influido por corrientes marinas frías y vientos predominantes del Pacífico Sur, con una barrera montañosa irregular en el Oeste y mesetas escalonadas descendentes hacia el Este, disectadas por valles latitudinales en donde escurren ríos alóctonos, posibilitó el dominio de un clima marítimo con temperaturas suavizadas $\mathrm{y}$, al mismo tiempo, con una marcada aridez en el ámbito extra-andino, inclusive, en el área costera. La intrincada historia geológica de Santa Cruz, que incluye un macizo precámbrico en el Noreste, distintos sucesos volcánicos, erosivos, sedimentarios, fallamientos, orogénesis, rupturas continentales, cambios climáticos, ingresiones marinas, glaciaciones y desglaciaciones en las sucesivas eras, repercutieron en sus suelos, que (a excepción del extremo Sur, de algunos valles fluviales y de ciertos ambientes húmedos del Oeste) se presentan poco evolucionados, típicos de espacios desérticos y subdesérticos. Consiguientemente, la vegetación que ha podido desarrollarse en estas condiciones ambientales ha sido la estepa en sus diferentes manifestaciones (arbustiva, subarbustiva, graminosa y sus combinaciones) y en áreas más extremas los desiertos y semidesiertos.

Indudablemente, ecosistemas como los mencionados resultan sumamente frágiles cuando sufren la intervención humana y, máxime, cuando ésta no toma en cuenta las propiedades intrínsecas de constitución y funcionamiento de los mismos. Es cierto que al tratarse de un espacio excepcional (pues no existen otros espacios continentales en las mismas latitudes australes, ni tampoco una combinación tan especial de factores naturales), no existió la posibilidad de saber cómo se comportarían estos ambientes ante los impactos de la actividad humana y, menos aún, presuponer los mismos con la escasez de conocimientos y tecnologías de fines del siglo XIX y comienzos del XX. La excepcionalidad de este espacio geográfico conforma múltiples escenarios sorprendentes, de los que se mencionarán sólo algunos: a) bosques en contacto con glaciares, resultado de la oceanidad climática; b) la estepa en contacto con el bosque, debido al fuerte gradiente pluviométrico generado por la irregularidad geomorfológica: al Este de las montañas que se hallan en contacto con las mesetas, el aire proveniente del Pacífico -que ya produjo precipitaciones al ascender por las laderas de barlovento- desciende y, a medida que lo hace, se va desecando; c) desiertos con amplitudes térmicas moderadas: inviernos y veranos atenuados (en otras palabras, "régimen hídrico árido en un

Publicado en formato digital: Dr. Dante Edin Cuadra. LA DINÁMICA SOCIOAMBIENTAL EN EL ESPACIO SANTACRUCEÑO. PECULIARIDADES DE LA RELACIÓN ENTRE LA POBLACIÓN Y EL MEDIO NATURAL DESDE UNA PERSPECTIVA GEOGRÁFICA. RESÚMENES DE TESIS. Revista Geográfica Digital. IGUNNE. Facultad de Humanidades. UNNE. Año 11. № 22. Julio - Diciembre. 2014. ISSN 1668-5180 Resistencia, Chaco. 
clima térmico templado frío marítimo" (Bruniard, E., 2009); d) desiertos con riqueza hidrológica: los suelos áridos y la vegetación xerófila contrastan con cielos predominantemente cubiertos (elevada nubosidad) y abundancia de aguas subterráneas que descienden de Oeste a Este; en Santa Cruz, si hay algo que sobra es el agua: el problema es su heterogénea distribución, pues la encontramos en las abundantes precipitaciones orográficas, en los grandes lagos, glaciares y picos nevados del Oeste, en los cursos fluviales que de Oeste a Este llevan sus caudales al Océano Atlántico; éste conforma un frente marítimo que supera los $900 \mathrm{~km}$ en el oriente de la provincia, aunque el tenor salino de las aguas no las hace utilizables directamente. Resulta paradójico, cómo en este ámbito el hombre se halla supeditado a las restricciones pluviométricas; en realidad, el agua está presente, pero no siempre disponible, pues las grandes distancias y los altos costos de las tecnologías de aprovechamiento y transporte, hacen que gran parte del espacio no tenga acceso a la misma.

El segundo impacto llegaría en la década del ' 40 , de la mano de la actividad minera, sobre todo de los combustibles (petróleo, gas natural y carbón), bajo el impulso de medidas de orden nacional, que motorizarían un gran dinamismo económico y demográfico en tres zonas de Santa Cruz: Noreste, Sudeste y Sudoeste.

Su compleja historia geológica le ha posibilitado disponer de una enorme y variada riqueza minera. El área más extendida ha sido la de la cuenca del Golfo de San Jorge al Norte del río Deseado, donde la extracción de petróleo y gas natural transformó literalmente a esas áreas ganaderas: el movimiento de suelos generado por las picadas sísmicas, las perforaciones, la instalación de ductos, piletas, caminos, bombas, tanques, la llegada masiva de trabajadores, el poderío empresarial -inicialmente de YPF y luego de las concesionarias- ha dejado huellas profundas en ese espacio, que debió afrontar los efectos negativos de la actividad, como los derrames de hidrocarburos y la contaminación de aguas superficiales y subterráneas, del suelo, la vegetación y el aire. El área Sudeste, también productora de petróleo y gas natural, por ser más restringida ha tenido menores impactos ambientales y dentro del espacio de explotación no existen centros urbanos, lo que representa menores riesgos para la población. En cuanto al Sudoeste de la provincia, las explotaciones son de carbón mineral con la modalidad de túneles subterráneos, que resultan menos agresivos para el ambiente en comparación con las extracciones a cielo abierto. No obstante, el procesamiento del mineral fuera de la mina, el material de desperdicio (ganga, polvillo, contenido de azufre) ha afectado a la cuenca del río Turbio y, consiguientemente, a la del Gallegos, a los suelos, napas freáticas y vegetación de la zona.

Entre las consecuencias pueden mencionarse los sucesivos incendios que genera el material depositado, por incineración natural en días de altas temperaturas, que en varias ocasiones se ha extendido a los bosques de las laderas montañosas colindantes. Puede afirmarse que la vulnerabilidad ambiental de estos espacios es elevada, en tanto que la vulnerabilidad social es menos notable durante el apogeo de la explotación, apareciendo con fuerza ante los primeros síntomas de decadencia de la actividad, pudiendo colapsar frente a una crisis severa de producción o al paralizarse la misma. La calidad de vida de los asentamientos mineros no suele ser óptima, dependiendo del grado de organización social e institucional que logra consolidar cada comunidad. Los desequilibrios demográficos suelen ser muy notables debido a la velocidad de conformación o crecimiento de estos núcleos, el arribo esporádico de hombres jóvenes y la diversidad de orígenes de los migrantes, lo que se acentúa en períodos críticos, cuando se producen despidos y expulsión de población. En esas instancias, la calidad de vida desciende bruscamente y la vulnerabilidad social alcanza niveles muy altos. La minería nunca constituye una actividad totalmente sustentable desde el punto de vista ambiental, dado que siempre deja algún grado de secuelas sobre el medio natural, pero sí puede encontrar etapas de equilibrio socioeconómico durante lapsos menores o mayores. Santa Cruz, Caleta Olivia y Pico Truncado evidencian cierta sustentabilidad sociodemográfica y económica, situación que no ha ocurrido con Cañadón Seco, ni con los pueblos de la cuenca del Turbio ubicados en torno a las minas. Los marcos legales nacionales, entre ellos el Código Minero, han fundamentado estas explotaciones y las nuevas legislaciones surgidas durante y después de los años '90 han sido diseñadas para intensificar la producción, al tiempo que exigen estudios de impacto y evaluación ambiental, que de cumplirse estrictamente, protegerían la salud humana y el ambiente. 
Un tercer factor que influye negativamente en los ambientes santacruceños es la gran cantidad de explotaciones mineras metalíferas y no metalíferas. Las más difundidas son las de rocas de aplicación (canteras de áridos, arenas, gravas y arcillas para la elaboración de ladrillos y otros materiales para la industria de la construcción), que dejan socavones de distintas dimensiones en gran parte del ámbito de las mesetas santacruceñas. En algunas áreas se explotan sales, fósforo (Bajo de San Julián), calcitas y dolomitas (Pico Truncado). El emprendimiento de mayor magnitud corresponde a la explotación de oro y plata de Cerro Vanguardia a unos $70 \mathrm{~km}$ al Noroeste de San Julián, cuyos efectos sobre el ambiente son muy notorios, dado que es a cielo abierto (socavones, remoción y deposición de material rocoso, aparte de los efectos del cianuro sobre el agua, el suelo, la vegetación y el aire, que se mantendrán durante muchos años, inclusive, luego de abandonarse la explotación). Estas actividades mineras, generalmente, están distanciadas de los centros urbanos, se rigen con las normativas vigentes y sus operarios residen en localidades cercanas o en campamentos instalados para el personal en sus proximidades. En el caso de Cerro Vanguardia, el impacto social y económico que ha tenido sobre Puerto San Julián ha sido muy importante, pues le ha concedido una dinámica inusual, que se ha traducido en nuevos hoteles, comercios y servicios.

La actividad pesquera en Santa Cruz se halla volcada al Mar Argentino, sobre todo en los puertos de Deseado y Punta Quilla (cerca de Puerto Santa Cruz) y, en menor medida, en otros puntos. Gran parte del negocio pesquero es manejado por el Estado Nacional, predominando la presencia de buques extranjeros autorizados a pescar en aguas jurisdiccionales argentinas. El control de estas actividades es bastante imperfecto, de modo que se estima que existe una sobreexplotación de algunas especies, en cuyo caso no podría hablarse de una actividad sustentable. La mayor preocupación ha sido la disminución de ejemplares de merluza de cola, langostinos y calamares, por lo que las autoridades nacionales y provinciales han implantado un sistema de vedas temporales y espaciales para proteger dichos recursos. Algunos efectos que periódicamente se sufren en las costas del Mar Argentino están vinculados con la pérdida de combustible de buques, que conforman manchas flotantes que las mareas traen a las costas, accidentes e, incluso, hundimiento de algunas embarcaciones. Los efectos de la pesquería sobre las poblaciones costeras son aún poco significativos, teniendo mayor notoriedad Puerto Deseado, donde se han instalado empresas de fileteado y envasado $y$, además, esta ciudad le provee combustibles y personal a los buques pesqueros de altura. Al Sur de Caleta Olivia el Estado Provincial ha construido un dique seco: una instalación que permite la reparación de barcos averiados y ofrece los servicios de mantenimiento de los buques que operan en esas latitudes.

Con respecto a los incipientes núcleos agrícolas que se hallan en la provincia (Los Antiguos, Perito Moreno, Gobernador Gregores, áreas próximas al río Santa Cruz, Calafate y Río Turbio), no se han reportado efectos contaminantes, al tiempo que -por la escala de desarrollo incipiente de la actividad-, se realiza dentro de parámetros sustentables. El clima frío no alienta la proliferación de plagas, de modo que no se utilizan agrotóxicos de riesgo ambiental y sanitario como en otros puntos del país. La calidad de vida en estos pequeños oasis es relativamente buena, la vulnerabilidad ambiental es baja, en tanto la vulnerabilidad social es algo más alta al tratarse -en su mayoría- de pequeños productores sin grandes capitales, ni tecnologías para superar períodos potencialmente críticos. La situación demográfica es medianamente equilibrada, dado que son explotaciones localizadas muy próximas a los centros urbanos (muchos de los emprendedores no están avocados a tiempo completo a la agricultura y desempeñan, paralelamente, ciertas actividades citadinas, en general vinculadas con la administración pública).

De la misma manera, la actividad turística, en términos generales, no ha evidenciado signos de impactos graves sobre el medio natural, aunque -lógicamente- donde hay confluencia humana siempre existen efectos negativos sobre el ambiente; no obstante, por las escalas y modalidades de desarrollo, son -por el momento- mitigables.

Por último, los asentamientos urbanos, como en todos los lugares, transforman intensamente el ambiente del sitio que ocupan y el de sus alrededores. Los efectos más reconocidos son: la presencia de basurales asociados a las quemas de residuos, la deposición de aguas servidas en ambientes fluviales, lacustres o marinos, la contaminación del aire y la presencia de actividades intensivas en sus entornos: agricultura, ganadería e incluso minería (hidrocarburos, carbón mineral y canteras).

Publicado en formato digital: Dr. Dante Edin Cuadra. LA DINÁMICA SOCIOAMBIENTAL EN EL ESPACIO SANTACRUCEÑO. PECULIARIDADES DE LA RELACIÓN ENTRE LA POBLACIÓN Y EL MEDIO NATURAL DESDE UNA PERSPECTIVA GEOGRÁFICA. RESÚMENES DE TESIS. Revista Geográfica Digital. IGUNNE. Facultad de Humanidades. UNNE. Año 11. № 22. Julio - Diciembre. 2014. ISSN 1668-5180 Resistencia, Chaco. 
Este fenómeno es observable prácticamente en todas las localidades de Santa Cruz. El viento intenso, sobre todo en primavera y verano, cumple la función de limpiar el aire de los contaminantes producidos por el hombre (humo, sustancias químicas, liberación de gas de cañerías y medidores), pero al mismo tiempo acarrea polvillo en suspensión de áreas erosionadas vecinas. La calidad de vida es muy variable entre ciudades y entre los propios sectores de una misma ciudad (buena en áreas céntricas y barrios acomodados y, baja o medio-baja en barrios y villas periféricas), pero en líneas generales es más alta que la de la población rural; algunas ciudades como Río Gallegos, Caleta Olivia, Pico Truncado, Puerto Deseado o Calafate gozan de mayor standard de vida y cuentan con una red de servicios diversificados, en tanto otras localidades más confinadas (Gobernador Gregores o Perito Moreno) poseen mayores limitaciones. La composición demográfica de los centros urbanos muestra un mayor equilibrio en comparación con las pequeñas localidades rurales o la población dispersa. Cuanto mayor gravitación espacial y demográfica alcanzan, logran ajustar mejor la distribución por sexos, por edad, el acceso a la educación, la repartición ocupacional, entre otros aspectos, como se observa en Río Gallegos y en Caleta Olivia.

\section{Bibliografía y fuentes consultadas}

Andrade, L., Bedacarratx, V., Alvarez, R. y Oliva, G. 2010. Otoño en la Estepa. Ambiente, ganadería y vínculos en la Patagonia Austral. Ed. La Colmena. Buenos Aires, Argentina.

Archivo Histórico de la provincia de Santa Cruz. Biblioratos de la Zona Militar de Comodoro Rivadavia. Río Gallegos, Santa Cruz. Consultas: años 1989 - 1990.

Baetti, Carlos 2000. ¿Despoblamiento o abandono de la zona rural en la Provincia de Santa Cruz?. En: "El Gran Libro de la Provincia de Santa Cruz". Ed. Milenio - ALFA Centro Literario. España.

Baetti, Carlos 1992. Unidades fisonómico-florísticas de Santa Cruz. Grupo Pastizales Naturales. INTA - CAP- UFPA. Inédito. Río Gallegos, Argentina.

Barbería, Elsa M. 1987. La distribución de la tierra pública en el Territorio de Santa Cruz entre 1880 y 1914. Cuaderno de Historia Regional $N^{\circ}$ 8. Univ. Nacional de Luján. Ed. EUDEBA. Buenos Aires, Argentina.

Barbería, Elsa M. 1985. La distribución de la tierra pública en Santa Cruz: Ley $N^{\circ} 1628$ de premios militares. Revista WAXEN N 1. IUSC. Río Gallegos, Argentina.

Barbería, Elsa M. 1988. Los cambios introducidos en la política de tierras. La Ley $N^{\circ} 4167$ y su aplicación hasta 1914". Revista WAXEN N² 2. IUSC. Río Gallegos, Argentina.

Barbería, Elsa M. 1995. Los dueños de la tierra en la Patagonia Austral, 1880-1920. Universidad Federal de la Patagonia Austral. Buenos Aires, Argentina.

Bertolani, Miguel A. 1989. Ecología y desertificación en Patagonia. Revista Patagonia Agropecuaria. Año V. No 16. Buenos Aires, Argentina.

Bifani, Paolo 1999. Medio ambiente y desarrollo sostenible. IEPALA Editorial. Madrid, España.

Bona, Aixa 2000. Actividades económicas en Santa Cruz. 1940-1990. En: "El Gran Libro de la Provincia de Santa Cruz". Ed. Milenio - ALFA Centro Literario. España.

Borrelli, Pablo y Oliva, Gabriel (Editores) 2001. Ganadería ovina sustentable en la Patagonia Austral. Tecnología de Manejo Extensivo. INTA. Ed. HerreGé \& Asociados. Bs. As., Argentina.

Borrero, L. y Carballo Marina, F. 2000. El poblamiento temprano: una mirada desde los estudios arqueológicos. En: "El Gran Libro de la Provincia de Santa Cruz". Tomo I. Ed. Milenio - ALFA Centro Literario. España.

Bosque Maurel, Joaquín 1983. Geografía, Historia y Geografía Histórica. En: Revista Estudios Geográficos. Instituto Juan Sebastián Elcano. Madrid, España.

Publicado en formato digital: Dr. Dante Edin Cuadra. LA DINÁMICA SOCIOAMBIENTAL EN EL ESPACIO SANTACRUCEÑO. PECULIARIDADES DE LA RELACIÓN ENTRE LA POBLACIÓN Y EL MEDIO NATURAL DESDE UNA PERSPECTIVA GEOGRÁFICA. RESÚMENES DE TESIS. Revista Geográfica Digital. IGUNNE. Facultad de Humanidades. UNNE. Año 11. № 22. Julio - Diciembre. 2014. ISSN 1668-5180 Resistencia, Chaco. 
Bruniard, Enrique D. 2009. Los paisajes de la diagonal árida: La Patagonia. Inédito. Resistencia, Argentina.

Bruniard, Enrique D. 1994. Los regímenes fluviales de alimentación sólida en la República Argentina. Academia Nacional de Geografía. Publicación Especial № 7. Buenos Aires, Argentina.

Bruniard, Enrique D. 1982. El Gran Chaco Argentino. Revista Geográfica 4. Universidad Nacional del Nordeste. Instituto de Geografía. Resistencia, Argentina.

Bueno Sánchez, Eramis 1994. Población y desarrollo. Enfoques alternativos de los estudios de población. La Habana, Cuba.

Buol, S., Hde, F. y Mc Craken, R. 1991. Génesis y clasificación de suelos. Ed. Trillas S.A., México.

Capellà i Miternique, H. y González, R. 2002. Geografía Cultural. Boletín de la A.G.E. № 34. Barcelona - Santiago de Compostella, España.

Capitanelli, Ricardo 1988. Patagonia: un medio duro, dominio de ovejas, con focos pioneros de ocupación e industrias promovidas. En: Roccatagliata, Juan (Coordinador): "La Argentina. Geografía General y los marcos regionales". Ed. Planeta S. A., Buenos Aires, Argentina.

Casas Torres, José M. 1982. Población, desarrollo y calidad de vida. Edic. Rialp S.A.- Madrid, España.

Censo de Población de Santa Cruz 1912. Dirección General de Estadística. Buenos Aires, Argentina.

Censo General de la Nación 1947. Dirección General de Estadística. Buenos Aires, Argentina.

Censo Nacional de los Territorios Nacionales de Neuquén, Río Negro, Chubut, Santa Cruz y Tierra del Fuego 1920. Consejo Nacional de Estadística y Censos. Ministerio del Interior. Buenos Aires, Argentina.

Censo Nacional de Población 1895. Poder Ejecutivo Nacional. Buenos Aires, Argentina.

Censo Nacional de Población y Vivienda 1980. INDEC. Buenos Aires, Argentina.

Censo Nacional de Población y Vivienda 1991. INDEC. Buenos Aires, Argentina.

Censo Nacional de Población y Viviendas 2001. INDEC. Buenos Aires, Argentina.

Censo Nacional de Población, Familias y Viviendas 1970. Resultados provisionales. INDEC. Buenos Aires, Argentina.

Censo Nacional de Población 1914. Dirección General de Estadística. Tomos I, II, III y IV: Población. Buenos Aires, Argentina.

Censo Nacional de Población 1960. Dirección General de Estadística. Buenos Aires, Argentina.

Censo Nacional de Población 1968. Provincia de Santa Cruz. Poder Ejecutivo. Buenos Aires, Argentina.

Censos Agropecuarios Nacionales 1988 / 2002. INDEC. Buenos Aires, Argentina.

CEPAL - Comisión Económica Para América Latina 2000. Pobreza y Vulnerabilidad Social. En: Panorama Social de América Latina 1999-2000, Santiago, Chile.

CEPAL 2002. Vulnerabilidad sociodemográfica: viejos y nuevos riesgos para comunidades, hogares y personas. Documento preliminar. Brasilia, Brasil.

Cepparo de Grosso, María E. 2000. El paisaje agropecuario de Santa Cruz. Una estructura homogénea. En: "El Gran Libro de la Provincia de Santa Cruz". Ed. Milenio - ALFA Centro Literario. España.

Cepparo, María E. 1987. El proceso de expansión pastoril en Santa Cruz y su relación con el crecimiento de la población. Revista Patagónica Nº 32 y 33. Buenos Aires, Argentina.

Publicado en formato digital: Dr. Dante Edin Cuadra. LA DINÁMICA SOCIOAMBIENTAL EN EL ESPACIO SANTACRUCEÑO. PECULIARIDADES DE LA RELACIÓN ENTRE LA POBLACIÓN Y EL MEDIO NATURAL DESDE UNA PERSPECTIVA GEOGRÁFICA. RESÚMENES DE TESIS. Revista Geográfica Digital. IGUNNE. Facultad de Humanidades. UNNE. Año 11. NN 22. Julio - Diciembre. 2014. ISSN 1668-5180 Resistencia, Chaco. 
Cepparo, María E. 1985. En la periferia de Santa Cruz: la minería. Su relación con la distribución de la población. Revista WAXEN N ${ }^{\circ}$ 1. IUSC. Río Gallegos, Argentina.

Cepparo, María E. 1986. La actividad pastoril de Santa Cruz: paisaje homogéneo, estructura invariable. Univ. Nacional de Cuyo. Fac. de Filosofía y Letras. Instituto de Geografía. Separata del Boletín de Estudios Geográficos. Vol. XXII, № 82 y 83. Mendoza, Argentina.

Chiozza, Elena (Directora) 1982. Atlas Total de la República Argentina. Vol. I y II. Hidrografía. Suelos. Provincia de Santa Cruz. Centro Editor de América Latina. Buenos Aires, Argentina.

Colantuono, María R. 1995. Neuquén. Una geografía abierta. Departamento de Geografía. Universidad Nacional del Comahue. Neuquén, Argentina.

Comité para el Desarrollo de la Cuenca del Río Santa Cruz 1978. Informe especial: Complejo hidroeléctrico de la cuenca del río Santa Cruz. Suplemento № 1 . Secretaría de Planeamiento de la Provincia de Santa Cruz. Río Gallegos, Argentina.

Cuadra, Dante E. y Oliva, Gabriel E. 1996. Ambientes Naturales de la Provincia de Santa Cruz. Revista Espacios No 6. UNPA. Río Gallegos, Argentina.

Cuadra, Dante E. 1995. Aportes a la climatología de Santa Cruz. Revista Espacios № 2. UNPA. Río Gallegos, Argentina.

Cuadra, Dante E. 2000. Dinámica de la estructura demográfica de Santa Cruz. En: García, Alicia y Mazzoni, Elizabeth (Coordinadoras): "El Gran Libro de Santa Cruz". Tomo II. Ed. Milenio - Alfa Ediciones. España.

Cuadra, Dante E. 2007. Territorio, cultura y toponimia: tres aspectos presentes en la apropiación de un espacio. $68^{\circ}$ Semana de Geografía - Congreso Nacional de Geografía. Posadas, Misiones. Editado por: Sociedad Argentina de Estudios Geográficos (GAEA). Buenos Aires, Argentina.

Cuadra, Dante y Alvarez, Hebe 2001. Recursos Naturales Renovables de Santa Cruz: su marco legal provincial y su correlato con la legislación nacional. UNPA. Inédito. Río Gallegos, Argentina.

Darwin, Charles (1839) 1997. Viaje de un naturalista alrededor del mundo. Documentos de 1839. Ed. Akal. Madrid, España.

Del Valle, H., Elissalde, N., Gagliardini, D. y Milovich, J. 2004. Mapa de Desertificación de la Provincia de Santa Cruz. CENPAT-CONICET, CAERCEM-CONICET, INTA E.E.A. Chubut. Trelew, Argentina.

Dirección de Catastro, Provincia de Santa Cruz 1989. Mapa catastral de Santa Cruz. Río Gallegos, Argentina.

Federación Lanera Argentina 2002. Boletín de Estadísticas Laneras. Buenos Aires, Argentina.

Foschiatti, Ana M. (Directora) 2009. Proyecto: Escenarios e imágenes de la vulnerabilidad del Nordeste Argentino: dimensiones críticas, estrategias y propuestas de mejoramiento. Dpto. de Geografía. UNNE. Resistencia, Argentina.

Galafassi, Guido 2000. La articulación sociedad-naturaleza y la problemática ambiental: una aproximación a su análisis. Universidad Nacional de Quilmes. Buenos Aires, Argentina.

García, Alicia y Mazzoni, Elizabeth (Coordinadoras) 2000. El Gran Libro de Santa Cruz. Tomo I y II. Ed. Milenio - Alfa Ediciones. España.

Gómez Lende, Sebastián 2003. División territorial del trabajo y productividad espacial. La minería aurífera en la Provincia de Santa Cruz. Revista Universitaria de Geografía. Vol. 12, № 1 y 2. Universidad Nacional del Sur. Bahía Blanca, Argentina.

Gómez Otero, Julieta 2000. Los indígenas: todo es según el cristal en que se mira. En: "El Gran Libro de Santa Cruz". Tomo I. Ed. Milenio - Alfa Ediciones. España.

Publicado en formato digital: Dr. Dante Edin Cuadra. LA DINÁMICA SOCIOAMBIENTAL EN EL ESPACIO SANTACRUCEÑO. PECULIARIDADES DE LA RELACIÓN ENTRE LA POBLACIÓN Y EL MEDIO NATURAL DESDE UNA PERSPECTIVA GEOGRÁFICA. RESÚMENES DE TESIS. Revista Geográfica Digital. IGUNNE. Facultad de Humanidades. UNNE. Año 11. № 22. Julio - Diciembre. 2014. ISSN 1668-5180 Resistencia, Chaco. 
González, Liliana 2000. Consecuencias ambientales de la actividad ganadera: la desertificación. En: "El Gran Libro de la Provincia de Santa Cruz". Ed. Milenio - ALFA Centro Literario. España.

Google Earth 2008. Europa Technologies. Data SIO, NOAA, U.S. Navy, NGA, GEBCO. US Dept of State Geographer.

I.G.M. (Instituto Geográfico Militar). Cartas topográficas de la Provincia de Santa Cruz. Escalas $1: 500.000$ y $1: 250.000$.

INTA (Instituto Nacional de Tecnología Agropecuaria) 2003. Estación Agropecuaria Santa Cruz. Estadísticas ganaderas. Río Gallegos, Argentina.

INTA E.E.A. Santa Cruz 1997. Relevamiento de vegetación. Trabajos de campo del Grupo Pastizales Naturales. Inédito. Años 1989 a 1995. Río Gallegos, Argentina.

INTA 2001. Ganadería ovina sustentable en la Patagonia Austral. Tecnología de Manejo Extensivo. Buenos Aires, Argentina.

INTA 1993. Proyecto de Prevención y Control de la Desertificación en Patagonia. Río Gallegos, Argentina.

Lafuente, Horacio 1981. La región de los Césares. Apuntes para una Historia Económica de Santa Cruz. Ed. de Belgrano. Buenos Aires, Argentina.

LUDEPA: Proyecto de Lucha contra la Desertificación en la Patagonia 1992. Sistema de Monitoreo Ecológico. Proyecto argentino-alemán. Informe de Trabajo. INTA-GTZ. Buenos Aires, Argentina.

Luque, Élida 2000. Santa Cruz y la cuestión limítrofe. En: "El Gran Libro de Santa Cruz". Tomo I. Ed. Milenio - Alfa Ediciones. España.

Malpartida, Alejandro y Lavanderos, Leonardo 1995. Aproximación a la Unidad SociedadNaturaleza, el Ecotono. Revista Chilena de Historia Natural No 68. Santiago, Chile.

Martinic Beros, Mateo 1977. La expansión económica de Punta Arenas sobre los territorios argentinos de la Patagonia y Tierra del Fuego entre 1885 y 1925. Anales del Instituto de la Patagonia. Punta Arenas, Chile.

Montes, Leopoldo y Oliva, Gabriel 1997. PRODESER: Sistema Regional de Soporte de Decisiones - Santa Cruz y Tierra del Fuego. Ed. HerreGé \& Asociados. Buenos Aires, Argentina.

Naciones Unidas 1996. Convención de Lucha contra la Desertificación. Documento base del Taller Nacional. Programa de Acción Nacional de Lucha contra la Desertificación. Río Gallegos, Argentina.

Newcombe, Robert 1976. Doce enfoques operativos en Geografía Histórica. En: Randle, Patricio (Editor): "Teoría de la Geografía". 10 Parte. Sociedad Argentina de Estudios Geográficos. Serie Especial № 3. Buenos Aires, Argentina.

Prego, Antonio (Coordinador) 1988. El deterioro del ambiente en la Argentina (suelo-aguavegetación-fauna). PROSA (Centro para la Promoción de la Conservación del Suelo y del Agua) FECIC (Fundación para la Educación, la Ciencia y la Cultura). Buenos Aires, Argentina.

Reboratti, Carlos 1999. Ambiente y Sociedad: conceptos y relaciones. Ariel. Buenos Aires, Argentina.

Rey Balmaceda, Raúl 1976. Geografía Histórica de la Patagonia (1870-1960). Tesis Doctoral. Ediciones Cervantes. Buenos Aires, Argentina.

Rey Balmaceda, Raúl 1988. La porción oceánica y la porción antártica, dos espacios en cuestión. En: "La Argentina. Geografía General y los marcos regionales". Roccatagliata, Juan (Coordinador). Ed. Planeta S. A., Buenos Aires, Argentina. 
Rial, Pablo; Oliva, Gabriel; González, Liliana y Cuadra, Dante E. 1994. LUDEPA, a joint Project of Germany and Argentina to fight against desertification in Patagonia. Ed. European Space Agency. Holanda.

Rivera Pabón, Jorge 2006. El papel de la Geografía en el estudio de la relación sociedadnaturaleza. Revista Luna Azul No 23. Manizales, Colombia.

Rocatagliata, Juan A. 1987. La Patagonia: perspectivas para su desarrollo. PROMEC. OIKOS, SENOC. Buenos Aires, Argentina.

Roccatagliata, Juan (Coordinador) 1988. La Argentina. Geografía General y los marcos regionales. Ed. Planeta S. A., Buenos Aires, Argentina.

Rodríguez, Mariela y Delrío, Walter 2000. Los tehuelches. Un paseo etnohistórico. En: "El Gran Libro de la Provincia de Santa Cruz". Tomo I. Ed. Milenio - ALFA Centro Literario. España.

SAGPYA (Secretaría de Agricultura, Ganadería y Pesca de la Nación) 2002. Datos ganaderos de la Provincia de Santa Cruz. Buenos Aires, Argentina.

Salazar Lea Plaza, Juan C. y Godañone, Rubén 1990. Suelos de la Provincia de Santa Cruz. En: Atlas de Suelos de la República Argentina, Módulo Santa Cruz. Tomo II. Secretaría de Agricultura, Ganadería y Pesca - Instituto Nacional de Tecnología Agropecuaria. Buenos Aires, Argentina.

Salvia, Agustín y Oliva, Miguel 1999. La Patagonia de los noventa. La Colmena. Buenos Aires, Argentina.

Sauer, Carl O. 1940. Hacia una Geografía Histórica. Discurso a la Asociación Norteamericana de Geógrafos. Baton Rouge, Louisiana, E.E.U.U. En línea: www.colorado.edu/geography

Secretaría de Ambiente y Desarrollo Sustentable de la Nación 1996. Plan Ambiental Nacional (PAN). Buenos Aires, Argentina.

Secretaría de Ambiente y Desarrollo Sustentable de la Nación 1996. Programa de Acción Nacional de Lucha contra la Desertificación. Documento Base. Cap. 4: Información de los Talleres Regionales. Región Patagónica. Buenos Aires, Argentina.

Secretaría de Energía de la Nación 2002. Anuarios estadísticos. Buenos Aires, Argentina.

Smith, C. T. 1976. Geografía Histórica: tendencias actuales y perspectivas futuras. En: Randle, Patricio (Editor): "Teoría de la Geografía". $1^{\circ}$ Parte. Sociedad Argentina de Estudios Geográficos. Serie Especial $N^{\circ} 3$. Buenos Aires, Argentina.

Soriano, Alberto 1956. Los distritos florísticos de la Provincia Patagónica. Revista de Investigaciones Agropecuarias. Buenos Aires, Argentina.

Subsecretaría de Pesca de la Provincia de Santa Cruz 2003. Datos de capturas y volúmenes anuales de producción. Inédito. Río Gallegos, Argentina.

Subsecretaría de Turismo de la Provincia de Santa Cruz 2003. Registros de Ingreso de turistas por localidades. Inédito. Río Gallegos, Argentina.

Súnico, Alejandro 2000. Explotación de los recursos mineros. En: "El Gran Libro de Santa Cruz". Tomo II. Ed. Milenio - Alfa Ediciones. España.

Velásquez, Guillermo 2001. Geografía, Calidad de vida y fragmentación en la Argentina de los noventa. Aportes para su estudio en Latinoamerica. Centro de Investigaciones Geográficas. Facultad de Ciencias Humanas. Universidad Nacional del Centro de la Provincia de Buenos Aires. Tandil, Argentina.

Wainerman, Catalina 2001. La trastienda de la investigación. Lumiere Ediciones. Buenos Aires, Argentina.

YCF (Yacimientos Carboníferos Fiscales). Administración Río Gallegos 1990. Folletos informativos y planillas de producción. Río Gallegos, Argentina. 
YPF (Yacimientos Petrolíferos Fiscales). Delegación Río Gallegos 1993. Anuarios estadísticos. Río Gallegos, Argentina.

Zárate, Rubén et al 2000. Patagonia Austral. Integración inconclusa y subdesarrollo inducido. HomoSapiens. Rosario, Argentina.

Zárate, Rubén; Artesi, Liliana; Buzzi, Martín, Cuadra, Dante y otros 2004. Conocimiento, periferia y desarrollo. Los nuevos escenarios en la Patagonia Austral. Ed. Biblos. Educación y Sociedad. Buenos Aires, Argentina.

Zarrilli, Adrián 2000. Transformación ecológica y precariedad económica en una economía marginal. El Gran Chaco Argentino (1890-1950). Revista Theomai. Estudios sobre Sociedad, Naturaleza y Desarrollo. No 1 . Buenos Aires, Argentina. 